Available online at GSC Online Press Directory

GSC Biological and Pharmaceutical Sciences

e-ISSN: 2581-3250, CODEN (USA): GBPSC2

Journal homepage: https://www.gsconlinepress.com/journals/gscbps

(RESEARCH ARTICLE)

\title{
Serum uric acid level among diabetic, hypertensive and diabetic-hypertensive patients attending specialist hospital Sokoto
}

\author{
Yale Bala Malam ${ }^{1,}{ }^{*}$, Yeldu Muhammed Haruna ${ }^{1}$, Dallatu Kabiru Muhammed ${ }^{1}$ and Danjuma Abubakar ${ }^{2}$ \\ ${ }^{1}$ Department of Chemical Pathology, School of Medical Laboratory Sciences, Usmanu Danfodiyo University, PMB 2346, \\ Sokoto, Nigeria. \\ ${ }^{2}$ Department of Chemical Pathology, Federal Medical Center Bida, Niger State, Nigeria.
}

Publication history: Received on 13 January 2020; revised on 22 January 2020; accepted on 23 January 2020

Article DOI: https://doi.org/10.30574/gscbps.2020.10.1.0010

\begin{abstract}
Elevated serum uric acid is associated with metabolic disorders such as insulin resistance, hypertension, diabetes, dyslipidaemia and also increases the risk of cardiovascular disease. This study evaluated serum uric acid and fasting plasma glucose in diabetic, hypertensive and diabetic-hypertensive patients. This study consist of 120 subjects including 30 diabetics, 30 hypertensives, 30 diabetic-hypertensive patients and 30 age- and sex-matched controls. The mean serum uric acid was significantly $(\mathrm{p}<0.001)$ higher in diabetic, hypertensive and diabetic-hypertensive patients when compared with those of controls. While the mean values of fasting plasma glucose were significantly $(p<0.001, p=0.007$ and $\mathrm{p}<0.001$ ) higher in diabetic, hypertensive and diabetic-hypertensive patients respectively when compared with those of controls. It was concluded from the finding of this study that, serum uric acid level and fasting plasma glucose increases significantly in diabetic, hypertensive and diabetic-hypertensive patients. It is recommended that serum uric acid and plasma glucose should be included as a routine investigation for the management of these groups of individuals to avoid the risk of cardiovascular diseases.
\end{abstract}

Keywords: Uric acid; Glucose; Hypertension; Diabetes; Patients; Controls

\section{Introduction}

Diabetes mellitus is a metabolic disorder characterized by the presence of chronic hyperglycaemia accompanied by greater or lesser impairment in the metabolism of carbohydrate, lipids and proteins [1]. The prevalence of diabetes in Nigeria is $4-10 \%$ [2]. In Sokoto, the reported prevalence of diabetes is $6.0 \%$ [3]. Three types of diabetes mellitus exist; type 1 which results from the failure of the pancreas to produce insulin, type 2 which results from an inability of the body to use insulin optimally and gestational diabetes which occurs in pregnant women without a previous diagnosis of diabetes [4].

Hypertension is a sustained elevation of resting systolic blood pressure (BP) $\geq 140 \mathrm{~mm} \mathrm{Hg}$, diastolic BP $\geq 90 \mathrm{~mm} \mathrm{Hg}$ or both [5]. It is divided into primary and secondary according to whether the cause is known or unknown [6]. Secondary hypertension is the one in which the cause is known, it is more common in children and occurs in less than $5 \%$ of people living with hypertension [6]. Kidney and vascular diseases are the most common causes of secondary hypertension. Primary; formerly referred to as essential hypertension is the one in which the cause is unknown and it is the most common, which occurs in over $95 \%$ of people living with hypertension [6]. The reported prevalence of hypertension varies around the world, with the lowest prevalence in rural India (3.4\% in men and 6.8\% in women) and highest in Poland (68.9\% in men and $73.5 \%$ in women) [7]. About $85 \%$ of uric acid is synthesized in our body and only $15 \%$ is by

\footnotetext{
${ }^{*}$ Corresponding author

E-mail address: yalebala@gmail.com
}

Copyright (C) 2020 Author(s) retain the copyright of this article. This article is published under the terms of the Creative Commons Attribution Liscense 4.0. 
food intake. Hyperuricaemia can result from increased urate production, decreased uric acid excretion by the kidneys, or a combination of the two mechanisms. Serum uric acid level can be a strong predictor of cardiovascular disease when combined with elevated blood pressure (even mildly elevated) [8]. Endothelial dysfunction may be a possible pathway linking uric acid and cardiovascular disease [8]. Uric acid is thought to play a pathogenic role in hypertension mediated by several mechanisms such as inflammation, vascular smooth muscle cell proliferation in renal microcirculation, endothelial dysfunction and activation of the renin-angiotensin-aldosterone system [9].

\section{Material and methods}

\subsection{Study area}

The study was carried out at specialist hospital Sokoto. Sokoto state is located at the extreme part of north-western Nigeria between longitude $3^{\circ}$ and $7^{\circ}$ east and between latitude $10^{\circ}$ and $14^{\circ}$ north of the equator. It shares borders with Niger-republic to the north, Kebbi state to the south-west and Zamfara State to the east [10]. The state covers a total land area of about 32,000 square kilometers and a population of 4,602298 million based on the 2013 projection [11]. Sokoto state has semi-arid climate and vegetation is largely Sudan savannah with annual rainfall between $500-1300$ $\mathrm{mm}$ and a temperature range between $15^{\circ} \mathrm{C}$ and over $40^{\circ} \mathrm{C}$ during warm days [10]. The indigenous inhabitant of the area is mainly Hausa and Fulani. Other ethnic groups resident in the area include Igbo, Nupe, Ibra, Igala etc. Hausa is the most spoken language. Traders and farmers form the greater part of this population, while there are civil servants, artisans and people of other occupational callings [12].

\subsection{Study population}

A total of 120 subjects were used for this study. This consists of 30 diabetic, 30 hypertensives, 30 diabetic-hypertensive and 30 control subjects attending specialist hospital Sokoto. The subject selection and clinical examination were performed by the consultant physicians in the clinic. In all the patients and controls, informed consent was obtained from each prior to the commencement of the study.

\subsection{Study design}

This is a cross-sectional study. At enrolment, a structured study questionnaire was used to elicit the subject demographic and socioeconomic data such as age, sex, marital status, occupation, present of any disease, family history among others.

The subjects were classified into the following groups:-

GROUP A: Diabetic patients $(n=30)$.

GROUP B: Hypertensive patients $(\mathrm{n}=30)$

GROUP C: Diabetic-hypertensive patients $(\mathrm{n}=30)$

GROUP D: Control subjects $(\mathrm{n}=30)$.

\subsection{Sample size determination}

The sample size for the study was calculated using the standard formula below [13].

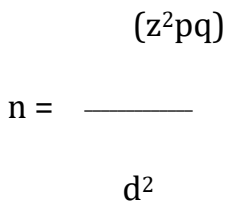

Where:

$\mathrm{n}=$ Number of the sample, for a population greater than $10,000, \mathrm{Z}=$ Standard normal deviation, usually set at 1.96 , which corresponds to the $95 \%$ confidence level, $\mathrm{P}=$ Prevalence rate of diabetes in Sokoto which is $6.0 \%$ [3]. $\mathrm{q}=$ complement of $\mathrm{p}$, which is $1-\mathrm{p}, \mathrm{d}=$ Degree of accuracy desired, usually set at 0.05 . 
Therefore the minimum sample size was calculated as follow:

$\mathrm{n}=(1.96)^{2}(0.06)(1-0.06)$

$(0.05)^{2}$

$\mathrm{n}=\underline{3.8416 \times 0.06 \times 0.94}$

0.0025

$\mathrm{n}=\underline{0.21666624}$

0.0025

$\mathrm{n}=86.666 \approx 87$

The calculated sample size is 87 .

\subsection{Ethical consideration}

Ethical approval of the study was obtained from the ethical and research committee of specialist hospital Sokoto, in accordance with the Helsinki. Informed consent was obtained from the participants enrolled in the research.

\subsection{Sampling techniques}

\subsubsection{Subject selection}

A convenient sampling technique was used to recruit the subjects until the desired sample-sized attained. In all the groups, at respective locations, subject selection, clinical examination and anthropometric measurements were carried out by consultant physicians. Written informed consent was obtained from each subject prior to the recruitment.

\subsubsection{Blood sample collection and processing}

Three (3) milliliters of venous blood was collected via venipuncture using a vacutainer syringe after an overnight fast of at least eight to ten hours from all the participants. One and a half milliliter was dispensed into a plane sterile vacutainer and fluoride oxalate tubes. The plain samples were allowed to clot and centrifuged at $4000 \mathrm{rpm}$ for $5 \mathrm{minutes}$. The sera obtained was rapidly harvested and stored at $-20^{\circ} \mathrm{C}$ until the analysis time. While plasma was obtained from the anti-coagulated samples after centrifugation.

\subsection{Measurement of blood pressure}

Blood pressure measurement was carried out by the consultant physician using manual blood pressure apparatus (sphygmomanometer and stethoscope) applied to a bared upper arm supported at the level of the heart with the individual in a relaxed mood. The brachial artery was partially occluded by inflating the blood pressure apparatus. The apparatus was then deflated until the pressure is low enough to allow blood to start flowing into the arm. The resumption of blood flow in the underline brachial artery generates turbulence that produces sound (Korotkoff sounds). The pressure corresponding to the beginning of blood flow (first Korotkoff sound) is the highest pressure in the artery and was detected using a stethoscope placed over the artery just below the cuff. This is called systolic blood pressure. The pressure corresponding to the disappearance of turbulence (the lowest pressure in the artery) is called diastolic pressure [14].

\subsection{Anthropometric measurement}

\subsubsection{Weight}

The weight was measured using an electronic balance beam scale. The subjects were weight with light clothes and no shoes. The weight was then read according to human resources and services administration to the nearest $0.1 \mathrm{~kg}$ [15].

\subsubsection{Height}

The subject stands erect and via footed on a Stadiometer. The height was read and recorded to the nearest $0.5 \mathrm{~cm}$ [15]. 


\subsubsection{Body mass index (BMI)}

The body mass index was calculated using the formula as follows:

$\mathrm{BMI}=\underline{\text { Weight } \mathrm{in} \mathrm{kg}}$

Height in $\mathrm{m}^{2}$

\subsection{Laboratory analytical methods}

\subsubsection{Estimation of serum uric acid}

This was based on the enzymatic colorimetric method described by Fossati et al., [16] using the reagent kit (LAB KIT Ltd, India).

\subsubsection{Estimation of plasma glucose}

This was based on the enzymatic colorimetric method described by Trinder [17] using the reagent kit (Agappe Diagnostics Ltd, India) for the assay.

\subsection{Statistical analysis}

The data generated were analyzed using the statistical package for social sciences (SPSS) version 23. The results of serum uric acid, fasting plasma glucose, blood pressure and anthropometric parameters were analyzed and expressed as mean plus/minus standard error of the mean (mean \pm SEM). The results of both the clinical and biochemical parameters were compared between different groups using a one-way analysis of variance (ANOVA) for matched samples. A p-value of less than $0.05(\mathrm{p}<0.05)$ was considered significant.

\section{Results}

Table 1 shows age and gender distribution of diabetic, hypertensive, diabetic-hypertensive patients and controls in their different age classes. A total of 30 diabetics (16 males and 14 females), 30 hypertensives (13 males and 17 females) and diabetic-hypertensive ( 6 males and 24 females) patients were recruited. A total of 30 apparently healthy subjects were recruited (20 males and 10 females) as controls. Most of the subjects were within the age range of 47-60 years.

Table 1 Age (years) and Gender Distribution of the Study Population

\begin{tabular}{|c|c|c|c|c|c|c|c|c|c|}
\hline \multirow{2}{*}{$\begin{array}{l}\text { Age } \\
\text { class }\end{array}$} & \multicolumn{2}{|c|}{ DM } & \multicolumn{2}{|l|}{ HTN } & \multirow{2}{*}{$\begin{array}{l}D-H \\
M \\
(n=6)\end{array}$} & \multicolumn{3}{|c|}{ C } & \multirow[t]{2}{*}{ Total } \\
\hline & $\begin{array}{l}M \\
(n=\end{array}$ & $\begin{array}{l}F \\
\text { ) }(n=14)\end{array}$ & $\begin{array}{l}M \quad I \\
(n=13)\end{array}$ & $F_{(n=17)}$ & & $\begin{array}{l}F \\
(n=24)\end{array}$ & $\begin{array}{l}M \\
(n=20)\end{array}$ & $\begin{array}{l}F \\
(n=10)\end{array}$ & \\
\hline $18-32$ & 2 & 3 & 1 & 1 & 5 & 4 & 10 & 8 & 34 \\
\hline $33-46$ & 2 & 3 & 2 & 3 & 1 & 10 & 1 & 2 & 24 \\
\hline $47-60$ & 11 & 8 & 10 & 9 & 5 & 10 & 4 & 5 & 62 \\
\hline Total & 15 & 14 & 13 & 13 & 11 & 24 & 15 & 15 & 120 \\
\hline
\end{tabular}

Table 2 shows the results of the demographic characteristics of the study population. The results show that $64.2 \%$ of the subjects were married, 70\% were predominantly Hausas and 65\% were on medications. 
Table 2 Demographic Characteristics of the Study Population

\begin{tabular}{lcc}
\hline Characteristics & No. of Subjects (n=120) & Percentage (100\%) \\
\hline Marital Status & 77 & 64.2 \\
Married & 37 & 30.8 \\
Single & 6 & 5 \\
Divorced & & \\
Ethnic Group & 84 & 70 \\
Hausa & 18 & 15 \\
Fulani & 3 & 2.5 \\
Yoruba & 3 & 2.5 \\
Igbo & 12 & 10 \\
Others & & \\
Occupation & 25 & 20.8 \\
Students & 13 & 10.8 \\
Civil Servant & 82 & 68.3 \\
Others & & \\
Medication & 78 & 63 \\
Yes & 42 & 35 \\
No & & \\
\hline
\end{tabular}

Table 3 shows serum uric acid and fasting plasma glucose in diabetic, hypertensive, diabetic-hypertensive patients and controls. The mean values of serum uric acid were significantly $(\mathrm{p}<0.001)$ higher in diabetic, hypertensive and diabetichypertensive patients when compared with controls. Also, the mean values of fasting plasma glucose concentration in diabetic, hypertensive and diabetic-hypertensive patients were significantly $(\mathrm{p}<0.001, \mathrm{p}=0.007$ and $\mathrm{p}<0.001$ respectively) higher when compared with those of controls.

Table 3 Serum Uric Acid and Fasting Plasma Glucose Level of the Study Population

\begin{tabular}{llll}
\hline GROUP & N & SUA (mg/dL) & FPG (mmol/L) \\
\hline 1 & 30 & $5.48 \pm 0.23$ & $10.30 \pm 0.73$ \\
2 & 30 & $5.95 \pm 0.30$ & $6.53 \pm 0.38$ \\
3 & 30 & $5.44 \pm 0.29$ & $7.61 \pm 0.41$ \\
4 & 30 & $3.27 \pm 0.06$ & $4.36 \pm 0.10$ \\
P-value & & $<0.001$ & $<0.001$ \\
Post hoc Test & & \\
Group 1 Vs 4 & & $\mathrm{P}<0.001$ & $\mathrm{P}=0.001$ \\
Group 2 Vs 4 & $\mathrm{P}<0.001$ & $\mathrm{P}<0.001$ \\
Group 3 Vs 4 & $\mathrm{P}<0.001$ & $\mathrm{P}<0.001$ \\
Group 1 Vs 2 & & $\mathrm{P}=0.517$ & $\mathrm{P}<0.001$ \\
Group 1 Vs 3 & & $\mathrm{P}=0.999$ & $\mathrm{P}=0.003$ \\
Group 2 Vs 3 & & $\mathrm{P}=0.445$ & \\
\hline
\end{tabular}

Values are mean \pm SEM; $n=$ Number of subjects; SUA= Serum uric acid; FPG= Fasting plasma glucose; $1=$ Diabetic $2=$ Hypertensive; $3=$ Diabetichypertensive; $4=$ Controls.

Table 4 shows the mean values of BMI and blood pressure in diabetic, hypertensive, diabetic-hypertensive patients and controls. The mean values of BMI were significantly $(p=0.023)$ higher in diabetic-hypertensive patients as compared 
with those of controls, also the mean values of SBP were significantly $(\mathrm{p}<0.001)$ higher in hypertensive patients as compared with those of controls.

Table 4 Anthropometric parameters and Blood Pressure of the Study Population

\begin{tabular}{llllll}
\hline Group & W (kg) & H $\left(\mathbf{m}^{2}\right)$ & BMI $\left(\mathbf{k g} / \mathbf{m}^{2}\right)$ & SBP $(\mathbf{m m H g})$ & DBP (mmHg) \\
\hline 1 & $63.93 \pm 2.59$ & $1.65 \pm 0.02$ & $23.62 \pm 0.98$ & $137.53 \pm 3.35$ & $84.13 \pm 2.69$ \\
2 & $68.83 \pm 3.04$ & $1.64 \pm 0.01$ & $25.54 \pm 1.10$ & $158.37 \pm 4.71$ & $96.97 \pm 2.83$ \\
3 & $68.40 \pm 2.51$ & $1.61 \pm 0.01$ & $26.19 \pm 0.87$ & $144.97 \pm 4.47$ & $91.40 \pm 3.11$ \\
4 & $60.50 \pm 1.25$ & $1.62 \pm 0.02$ & $22.50 \pm 0.59$ & $125.97 \pm 3.74$ & $88.10 \pm 0.65$ \\
P-value & 0.012 & 0.218 & 0.060 & $<0.001$ & 0.004 \\
\hline Post hoc Test & & & & & $\mathrm{p}=0.197$ \\
\hline G 1 Vs 4 & $\mathrm{p}=0.752$ & $\mathrm{p}=0.677$ & $\mathrm{p}=0.814$ & $\mathrm{p}<0.001$ & $\mathrm{p}=0.067$ \\
G 2 Vs 4 & $\mathrm{p}=0.080$ & $\mathrm{p}=0.815$ & $\mathrm{P}=0.086$ & $\mathrm{p}=0.008$ & $\mathrm{p}=0.790$ \\
G 3 Vs 4 & $\mathrm{p}=0.106$ & $\mathrm{p}=0.976$ & $\mathrm{p}=0.023$ & $\mathrm{p}=0.003$ & $\mathrm{p}=0.003$ \\
G 1 Vs 2 & $\mathrm{p}=0.489$ & $\mathrm{p}=0.995$ & $\mathrm{p}=0.439$ & $\mathrm{p}=0.577$ & $\mathrm{p}=0.179$ \\
G 1 Vs 3 & $\mathrm{p}=0.568$ & $\mathrm{p}=0.418$ & $\mathrm{p}=0.191$ & $\mathrm{p}=0.102$ & $\mathrm{p}=0.403$ \\
G 2 Vs 3 & $\mathrm{p}=0.999$ & $\mathrm{p}=0.566$ & $\mathrm{p}=0.958$ & & \\
\hline
\end{tabular}

Values are mean \pm SEM; H= Height; $\mathrm{W}=$ Weight; BMI= Body mass index; $\mathrm{SBP}=$ Systolic blood pressure; $\mathrm{DBP}=\mathrm{Diastolic}$ blood pressure; $\mathrm{G}=\mathrm{Group}$; VS= versus; 1=; Diabetic 2= Hypertensive; 3= Diabetic-hypertensive; 4= Controls.

\section{Discussion}

Uric acid is a ubiquitous byproduct of purine metabolism in humans and higher primates, Hyperuricaemia has been associated with hypertension, diabetes mellitus, and metabolic syndromes and even increase the risk of cardiovascular diseases [18].

The current study demonstrated that most of the study subjects are Hausas (70\%) and the majority of them are married $(64.2 \%)$. Most of them are within the age range of 47-60, and about 78 (65\%) were on medications.

The finding of significant $(\mathrm{p}<0.001)$ increase in serum uric acid among diabetic, hypertensive and diabetic-hypertensive patients as compared with controls, agreed with the previous studies of Babikr et al., [19] and Venkateswara and Vanukuri, [20]. This could be due to the effect of insulin which may stimulate sodium and urate reabsorption in the proximal tubule which leads to increase serum uric acid level. The increase in the level of uric acid in this patient may be due to the diuretic activity of some drugs in which the patients used for their treatment.

Increased serum uric acid was reported in subjects with obesity, insulin resistance, and dyslipidaemia. Hyperuricaemia frequently occurs because insulin stimulates sodium and urate reabsorption in the proximal tubule [21]. The uric acid level is increased in subjects with renal disease as a result of decreased glomerular filtration rate (GFR) and renal urate excretion [22]. Diuretics increase serum uric acid but the clinical relevance of these effects remains uncertain [23]. It has been suggested that the increase in serum uric acid caused by diuretic treatment may partially offset the benefits of blood pressure reduction [24].

Uric acid causes hypertension in a rat model through the activation of the renin-angiotensin system, down-regulation of nitric oxide, and induction of endothelial dysfunction and vascular smooth muscle proliferation [25]. Uric acid is thought to play a role in hypertension mediated by several mechanisms such as inflammation, vascular smooth muscle cell proliferation in renal microcirculation, endothelial dysfunction and activation of the renin-angiotensin-aldosterone system [26].

The finding of significant $(\mathrm{p}<0.001, \mathrm{p}=0.007, \mathrm{p}<0.001)$ increased in fasting plasma glucose of diabetic, hypertensive and diabetic-hypertensive patients respectively, as compared to those of controls is consistent with the report of [27]; [19]; 
[20]. The hyperglycaemia may be due to stress, ageing and an imbalance of glucose production from the noncarbohydrate source such as lipid, protein. Multiple factors in an older person contributed to such an imbalance of glucose regulation [28]. The hyperglycaemic condition may result due to insulin resistance, viral infection, inflammation and obesity [29].

The finding of significant ( $\mathrm{p}=0.023)$ increased in BMI of diabetic-hypertensive patients as compared with those of controls agreed with the study of [30]. Similarly, the finding of significant $(\mathrm{p}<0.001)$ increased in SBP of hypertensive patients as compared with those of controls also agreed with the study of [30]. The increase in BMI may be a result of impaired glucose metabolism which results in lipogenesis hence increase the body mass, while the increased SBP may be a result of increased deposition of lipid most especially cholesterol along the blood vessels.

\section{Conclusion}

There was a significant increase in the mean of serum uric acid and fasting plasma glucose among diabetic, hypertensive and diabetic-hypertensive patients as compared with those of controls. Future studies should focus on evaluating the effect of hyperuricaemia as a risk factor for the development of cardiovascular disease in this group of patients.

\section{Compliance with ethical standards}

\section{Acknowledgments}

We thank the entire staff of the specialist hospital and chemical pathology laboratory, UDUTH Sokoto for their support towards the successful completion of this work.

\section{Disclosure of conflict of interest}

This article is not the object of any conflict of interest and has not been submitted to other journals for publication. Therefore, we authorize the journal to publish it.

\section{Statement of ethical approval}

Ethical approval of the study was obtained from the ethical and research committee of specialist hospital Sokoto.

\section{Statement of informed consent}

Informed consent was obtained from the participants enrolled in the research. The participants were fully informed about the research aim and their confidentiality was maintained.

\section{References}

[1] Baynes HW. (2015). Classification, Pathophysiology, diagnosis and management of diabetes mellitus. Journal of Diabetes and Metabolism, 6, 541.

[2] World Health Organization. (2016). Diabetes country profiles.

[3] Makusidi MA, Liman HM, Yakubu A, Isah MD and Jega RM. (2013). Prevalence of non-communicable diseases and its awareness among inhabitants in Sokoto metropolis: outcome of a screening program for hypertension, obesity, diabetes mellitus and overt Proteinuria. Arab Journal of Nephrology and Transplant, 6(3), $189-191$.

[4] Fowler MJ. (2008). Complications of diabetes. Clinical Diabetes, 26(2), 77-82.

[5] World Health Organization. (1999). Diagnosis and classification of diabetes mellitus and its complications, Geneva, 1-59.

[6] Isezuo SA. (2015).People living with hypertension. Inaugural lecture published by the central coordinating committee for Usmanu Danfodiyo University Sokoto inaugural lectures and seminars, ISBN, 978-978-900-733-2, 18-48.

[7] Keaney PM, Whelton M, Reynolds K and Jiang H. (2004). Worldwide prevalence of Hypertension: a systemic review. Journal of Hypertension, 22, 11-19. 
[8] Khosla UM, Zharikov S and Finch JL. (2005). Hyperuricaemia induces endothelial dysfunction. Kidney International Journal, 67, 1739-1742.

[9] Mishra A, Poonam G, Arvaid G, Surjit KV, Ajeet KC and Dharamveer S. (2017). Prevalence and association of hyperuricaemia in patients of newly diagnosed essential hypertension. International Journal of Contemporary Medical Research, 4(2), 404.

[10] Sokoto State Business Directory (SSBD). (2007). A publication of the Commerce Department, ministry of commerce, industry and tourism, Sokoto, 14-18.

[11] United Nations population found. (2013). Sokoto state population projection, UNFPA; Nigeria.

[12] Imam A. (2006). Prevalence of coliforms bacteria on enviroment surface in day care centre and nursery school metropolis. MPH Dissertation; Usmanu Danfodiyo University Sokoto.

[13] Araoye MO. (2003). Research methodology with statistics for health and social sciences NATHADEX Publishers. ODO-Okun Sawmill Ilorin, Nigeria, 115-129.

[14] Perloff D, Grim C, Flack J, Frohlich ED, Hill M, McDonald M and Morgenstern BZ. (1993). Human blood pressure determination by sphygmomanometer. Circulation Journal, 88(5), 2460-2465.

[15] Human Resources and Services Administration (HRSA). (2010). Maternal Child Health Bureau and the Centers for Disease Control and Prevention. Growth Charts Training Modules.

[16] Fossati P, Prencipe L and Berti G. (1984).Use of 3, 5-dichloro-2-hydroxyl-benzene Sulfonic acid and 4aminophenazone Chromogenic system in direct enzymatic assay of uric acid in serum and urine. Clinical Chemistry, 26, 227-231.

[17] Trinder P. (1969).Determination of glucose by enzymatic method. Journal of Clinical Pathology, 22(2), 161-170.

[18] Choi HK, Mount DB and Reginato AM. (2005).Pathogenesis of gout. Annal of International Medicine, 143, 499516.

[19] Babikr GW, El-hussein A, Abdelraheem A, Mohammed H, Magzoub A and Almasary M. (2016). The correlation of uric acid levels with glycemic control in type 2 diabetic patients. Biomedical and Pharmacology Journal, 9(3), 105-108.

[20] Venkateswara TM and Vanukuri NK. (2016). A Study of serum uric acid level in type 2 diabetes mellitus and its association with cardiovascular risk factors. International Archives of Integrated Medicine, 3(12), 148-155.

[21] Galvan AQ, Natali A, Bald S, Frascerra S, Sanna G, Ciociaro D and Ferrannini, E. (1995).Effect of insulin on uric acid excretion in humans. American Journal of Physiology, 268, 1-5.

[22] Johnson RJ, Kang D, Feig D, Kivlighn S, Kanellis J, Watanabe S, Tuttle KR, Rodriguez IB, Herrera-Acosta J and Mazzali M. (2003). Is there a pathogenetic role for uric acid in hypertension and cardiovascular and renal disease? Hypertension, 41(7), 1-8.

[23] Pahor M, Shorr RI, Somes GW, Cushman WC, Ferrucci L and Bailey JE. (1998). Diuretic-based treatment and cardiovascular events in patients with mild renal dysfunction enrolled in the systolic hypertension in the elderly program. Archive of International Medicine, 158, 134-1345.

[24] Alderman MH, Cohen H, Madhavan S and Kivlighn S. (1999). Serum uric acid and cardiovascular events in successfully treated hypertensive patients. Hypertension, 34, 144-150.

[25] Vakil A, Vrkariya P, Barafiwala V, Gamit K, Patel D and Doctor N. (2017). Study of serum uric acid level in hypertension. Journal of Dental and Medical Sciences, 16(4), 69-73.

[26] Forman JP, Choi H and Curhan GC. (2007). Plasma uric acid level and risk for incident hypertension among men. Journal of American Society of Nephrology, 18, 287-92.

[27] Talwar T, Tanwar L, Gupta M and Singal KK. (2017). Study of serum uric acid level in type 2 diabetes mellitus patients. Journal of Dental and Medical Sciences, 16(10), 83-89.

[28] Lee PG and Halter JB. (2017). The pathophysiology of hyperglycaemia in older adults: Clinical considerations. Diabetes Care, 40, 444-452.

[29] Saunders C, Byrne CD and Guthrie B. (2013). External validity of randomized controlled trials of glycemic control of vascular disease. Diabetes Medicine, 30, 300-308. 
[30] Poudel B, Yadav BK, Yadav BK, Kumar A, Jha B and Raut KB. (2014). Serum uric acid level in newly diagnosed essential hypertension in a Nepalese population: A hospital based cross sectional study. Asian Pacific Journal of Tropical Biomedicine, 4(1), 59-64.

\section{How to cite this article}

Yale BM, Yeldu MH, Dallatu KM and Danjuma A. (2020). Serum uric acid level among diabetic, hypertensive and diabetichypertensive patients attending specialist hospital Sokoto. GSC Biological and Pharmaceutical Sciences, 10(1), 109-117. 